Document downloaded from:

http://hdl.handle.net/10251/83370

This paper must be cited as:

Burguete Llorens, PL.; Corma Canós, A.; Hitzl, M.; Modrego Latorre, R.; Ponce Ballester, E.; Renz, M. (2016). Fuel and chemicals from wet lignocellulosic biomass waste streams by hydrothermal carbonization. Green Chemistry. 18(4):1051-1060. doi:10.1039/C5GC02296G

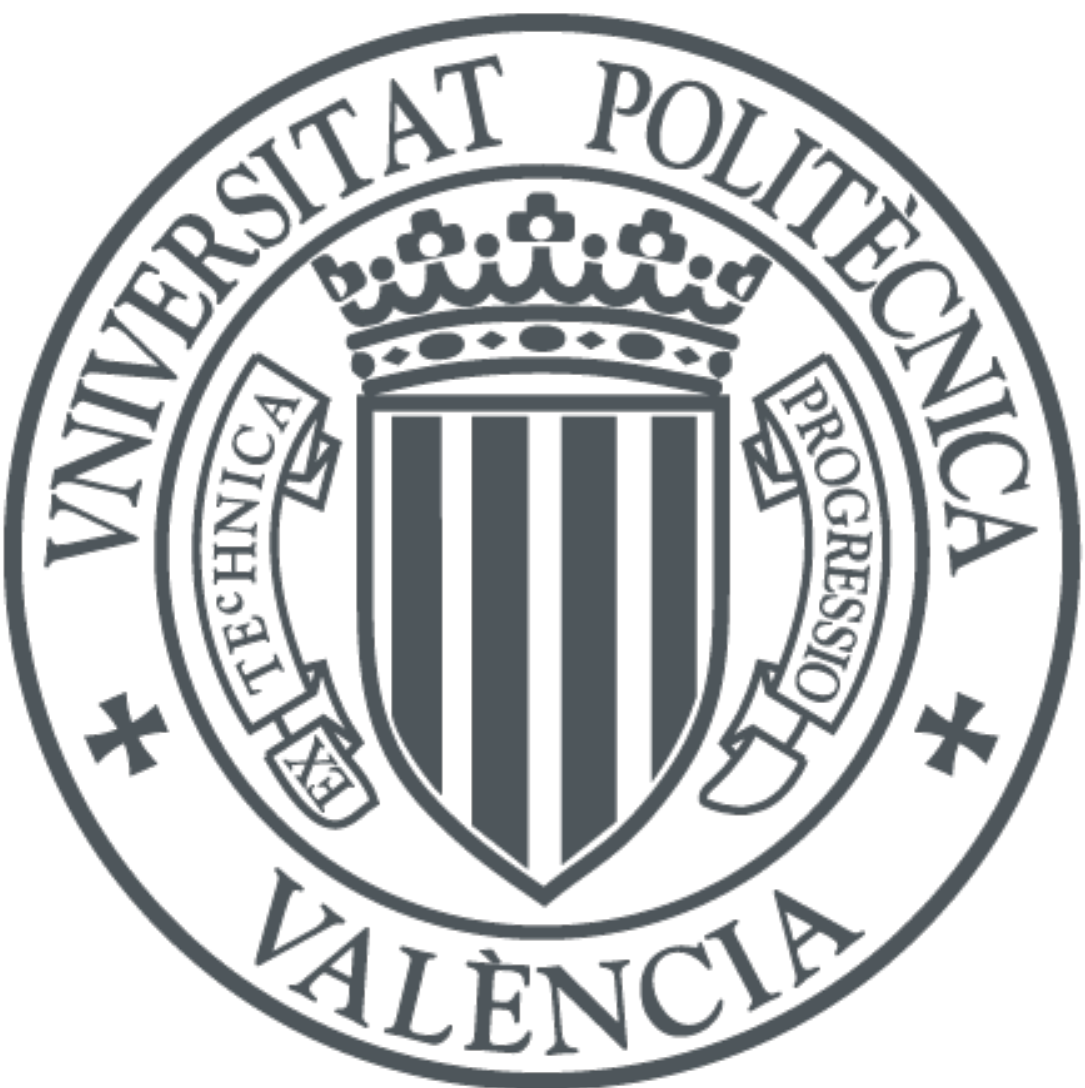

The final publication is available at

http://doi.org/10.1039/c5gc02296g

Copyright Royal Society of Chemistry

Additional Information 


\title{
Fuel and chemicals from wet lignocellulosic biomass waste streams by hydrothermal carbonization
}

\author{
Pedro Burguete ${ }^{\mathrm{a}}$, Avelino Corma ${ }^{* \mathrm{a}}$, Martin Hitzl ${ }^{\mathrm{b}}$, Rubén Modrego ${ }^{\mathrm{a}}$, Estefanía Ponce ${ }^{\mathrm{b}}$, \\ Michael Renz*a \\ a Instituto de Tecnología Química (UPV-CSIC), Universitat Politècnica de València- \\ Consejo Superior de Investigaciones Científicas, Avenida de los Naranjos s/n, 46022 \\ Valencia, Spain. \\ ${ }^{\mathrm{b}}$ Ingelia, S.L., C/Jaime Roig 19; 46010 Valencia, Spain.
}

\begin{abstract}
Most valorization processes for biomass waste require dry raw material or at least a relatively low amount of residual humidity. In contrast, the hydrothermal carbonization (HTC) is a valorization process for lignocellulosic biomass which uses water as reaction medium. The product, hydrochar, can be used as dry solid fuel being the post-process drying procedure much more energy-efficient. Herein, three lignocellulosic biomass waste feedstocks, i.e. the organic fraction of municipal solid waste (OFMSW), orange peel waste (OPW) and the residues of a pepper plantation, were processed by HTC on a ton scale and the product evaluated as solid fuel in form of pellets for domestic use (EN ISO 17225). A critical property of the product is the ash content which has to be adjusted by post-treatment. The ash content was achieved to below the established limit by acid treatment with sulfuric acid. An implementation of the treatment into the pilot plant is straightforward.

An organic liquid fraction was obtained as additional effluent in the pilot plant depending on the biomass feedstock. For instance, limonene in a mixture with other monoterpenes was separated when orange peel waste was processed, approximately 3 $\mathrm{wt} \%$ of dry matter. It is further shown at laboratory scale that the monoterpene mixture can be directly used or can easily be transformed into para-cymene, a fragrance compound, by catalytic dehydrogenation. Therefore, the HTC process can be considered as a source for valuable apolar platform molecules derived from lignocellulosic biomass waste in addition to the production of hydrochar.
\end{abstract}




\section{Introduction}

Biomass waste feedstocks have to be considered as resources rather than as worthless waste, in contrast to the more popular view which classifies them as low-value, useless and, even more, associates them to disposal costs. ${ }^{1-3}$ Probably, the most prominent example of undervalued biomass streams is generated by private households: the organic fraction of municipal solid waste. Most other neglected biomass feedstocks derive from value chains. Hereby, an impression of low value and of uselessness is derived from the fact that these streams cannot be valorized anymore in the same industrial sector.

There are manifold examples of this type of biomass feedstock. The concept applies for instance to the digestate from biogas production plants. ${ }^{4,5}$ Hence, methane is considered the valuable product and digestate a residue remaining from the solid biomass. Similarly, many residues are produced in the food processing industry consisting of the non-edible parts. ${ }^{6-8}$ The production of food waste can be illustrated by means of the example of tomato pomace. ${ }^{7}$ Tomato is the second most important vegetable crop with an annual production of more than $100 \cdot 10^{6}$ tons. ${ }^{9}$ Most of the fruit (in Turkey for instance $80 \%)^{10}$ is processed to paste leaving a residue of tomato pomace, consisting of peel and seeds, of $5 \mathrm{wt} \%{ }^{7}$ This sums up to more than $5 \cdot 10^{6}$ tons of a waste with $75 \%$ water content. $^{10,11} \mathrm{~A}$ common feature of all these waste streams is their high water content, which causes depreciation of these feedstocks. Water hinders industrial but also agricultural exploitation and thermal drying is an energy-wasting process. For instance, tomato pomace can be used as animal feed but has a low protein content ${ }^{7,11}$ and spoils after two days. ${ }^{10,12}$ Alternative incineration is energy intensive due to the high water content and the low calorific content (energy efficiency of about 15\%). ${ }^{7}{ }^{13}$ The high water content in combination with nutrients favor bacteria growth ${ }^{7}$ when stored or landfilled. As a consequence, GHG such as methane are produced. ${ }^{2} 9$ Additionally, disposal of food waste can have a significant economical impact. For instance, an amount of 10 million dollar (landfill fees) has been estimated for disposal of apple pomace in USA annually. ${ }^{7}$ These examples demonstrate that surplus humid biomass is not a neutral and innocuous material but might also raise economical and environmental issues.

As a further characteristic, biomass residues often involve interesting chemical compounds. For instance, Norway spruce knots, unsuitable for pulping and therefore removed before the process, have a significant content of lignan hydroxymatairesinol. ${ }^{14-}$ 
16 The latter organics have anticarcinogenic and antioxidative properties. Another, very prominent example of chemical compounds in biomass is the monoterpene limonene which is abundant in citrus peel waste. It has been recognized that due to its antimicrobial properties, limonene hinders ethanol, succinic acid and biogas production from this feedstock. ${ }^{17-19}$ In cultivation areas of these fruits like Florida, Brazil and the Mediterranean Basin, the potential of limonene has been recognized and manifold applications are contemplated. ${ }^{20}$ The use as eco-friendly solvent is an outstanding application since it has similar characteristics as halogenated or aromatic solvents which rise health issues. ${ }^{21}$ However, limonene has to be extracted from small closed cavities in the peel, the oils sacs or glands. ${ }^{19}$ This requires a considerable amount of energy with the corresponding impact on the economical balance. Hence, fossil oil-derived alternatives might be more competitive as solvents. Therefore, it has been proposed to convert limonene into value-added chemicals, e.g. by sulfonation, and to use it as an acidic catalyst. ${ }^{22}$ As a summary, it can be seen here that the potential of production of interesting chemical compounds from biomass, which has reached the end of its value chain, is promising. Production cost is the most important variable which has to be optimized. Commercializing also the solid residue of the extraction process, e.g. as solid fuel, could improve the economical balance.

Waste is often valorized thermally as energy source. As already stated, in the case of wet biomass direct incineration has low energy efficiency and therefore appropriate processes should be developed to transform it into value added energy carriers. Hence, wet biomass waste streams, such as food wastes, have been considered for production of hydrogen, biogas, ethanol or biodiesel as renewable energy sources. ${ }^{11,13,23}$ Application hurdles are associated most notably with the transportation and the high initial capital costs of biorefineries. ${ }^{11}$ For a material with $50 \%$ humidity, the same amount of water as dry biomass has to be transported, without any revenue. For $80 \%$ humidity it is a ratio of four to one, water to biomass. Alternatively, biomass can be converted into biochar and bio-oil for energy supply by pyrolysis. ${ }^{24,} 25$ However, drying of biomass for conditioning of the material for the process increases the operation costs significantly when humidity is high. ${ }^{26}$ Accordingly, the water content is a decisive factor for the valorization and a highly adapted process has to be applied.

Having in mind the elevated humidity content of the food waste, it seems to be straightforward to use water directly as reaction medium. Hence, this is done in a hydrothermal treatment of the biomass, ${ }^{1}$ generally called hydrothermal carbonization 
(HTC). The HTC process has received very much attention after its rediscovery for biomass transformation by Antonietti and Titirici in $2007 .{ }^{27}$ During this process, biomass is dehydrated in the presence of water at temperatures around $200{ }^{\circ} \mathrm{C}$ and under autogenous pressure. The desired product is the peat-like HTC-carbon or hydrochar. The denomination "hydrochar" is recommended for the product of the HTC process by the European Biomass Industry Association. ${ }^{28}$ First evaluations show that the HTC process could be energy efficient for wet biomass and net energy can be incorporated into a carrier. ${ }^{1}$ Hence, employing the HTC process wet biomass could be transformed into a carbon powder in an energy efficient way.

In any case, it has to be taken into account that the product has to be dried to below 10 wt $\%$ of humidity for being used as solid fuel. ${ }^{29}$ For hydrochar, this is less energy consuming than drying the initial raw material since down to $50 \mathrm{wt} \%$, water can be removed by energy-economic mechanical dewatering (filter press) which might already remove $75 \%$ of initial humidity. Furthermore, removal of the remaining water by thermal drying to reach the final water content is less energy consuming. Plant structure is broken down facilitating water diffusion and water is retained less by a less polar carbon material (lower oxygen content). For all these reasons drying hydrochar for its use as solid fuel is more energy efficient than drying the humid raw material.

The humidity and the general suitability of biomass-derived energy carriers has been regulated, for instance for non-industrial use in the norm EN ISO $17225 .{ }^{30}$ Parameters such as ash content, maximum nitrogen or sulfur content are specified. Two classes of carrier are considered for biomass derived from green prunings or fruits with more restrictive limits for a higher quality product. For instance, ash content may be $10 \mathrm{wt} \%$ for the lower quality and has to be less than $5 \mathrm{wt} \%$ for the higher quality. ${ }^{29}$ Limits for nitrogen content are 2.0 and $1.5 \mathrm{wt} \%$, respectively, and the sulfur maximum content is $0.2 \mathrm{wt} \%$ in both cases. ${ }^{29}$ The hydrochar has the potential to fulfill these specifications, when produced employing garden pruning biomass. ${ }^{31}$ Average ash content is approximately $13.5 \mathrm{wt} \%$, the sulfur content $0.1 \mathrm{wt} \%$ and the average nitrogen content approximately $1.7 \mathrm{wt} \%$.

Herein, we extend the pilot-plant data on a ton-scale from garden prunings ${ }^{31}$ to food waste and the organic fraction of municipal solid waste (OFMSW). We report a complete mass balance and all important properties of the hydrochar for its use as solid fuel. Possibilities of adjusting the ash content to the characteristics of a solid biomassderived fuel as described in norm EN ISO 17225-6 for both quality standards are 
evaluated and the implantation into the pilot plant process is discussed. In the pilot plant trials it was further observed that with certain biomass feedstocks organic liquids can be separated as for instance in the case of orange peel waste. Up-grading to a commercial product is proposed in the case that the commercial value of the liquid is moderate due to the low concentration of single compounds in the monoterpene mixture.

\section{Experimental part}

\section{Description of the pilot plant}

The pilot plant and its post-treatment facility has already been described in literature. ${ }^{31}$ Shortly, the reactor is a vertical pressure cylinder which is operated between 180 and $230{ }^{\circ} \mathrm{C}$ and autogenous pressure of the water mixture. It is designed for continuous operation with a capacity of 3-5 tons of biomass per day. Humid biomass is fed from the bottom and a water hydrochar slurry is removed also from the bottom. After the process ash can be partly removed by physical means and humidity is reduced to approximately $50 \mathrm{wt} \%$. Hydrochar can be further dried thermally and pelletized to produce solid fuel.

\section{Analysis of the biomass and the hydrochar}

For determination of humidity, samples (approx. $1 \mathrm{~g}$ ) were weighed exactly and dried at $100{ }^{\circ} \mathrm{C}$ in an oven overnight. The humidity content was determined by weight difference.

The ash content was determined as described in UNE 32-004-84. The sample was milled in a planetary ball mill to a particle size $<0.2 \mathrm{~mm}$. Approximately $1 \mathrm{~g}$ (weighed exactly) was placed in a crucible and heated in a muffle furnace from room temperature to $815^{\circ} \mathrm{C}$ with a heating rate of $3 \mathrm{~K} / \mathrm{min}$. The temperature $\left(815^{\circ} \mathrm{C}\right)$ was maintained for one hour. The residue obtained is the ash of the sample. The ash content is calculated by the following formula:

Ash content $/ \%=$ Mass/g (ash) $/$ Mass/g (sample)*100

Ash content was also checked by calcination at $550{ }^{\circ} \mathrm{C}$ and very similar values and ash composition were obtained. The alkali content $(\mathrm{Na}+\mathrm{K})$ was $5 \%$ or lower in all cases (cf. Table S1).

For elemental analysis (CHNS), samples were milled $(<0.2 \mathrm{~mm})$ and dried. Samples were analyzed on a Fisons EA 1108 CHNS-O apparatus. The values are stated on a dry and ash-free basis. 
The composition of the ashes was determined by inductively coupled plasma optical emission spectroscopy (ICP OES). Therefore, a sample (20-30 mg) was disaggregated in a $\mathrm{HNO}_{3} / \mathrm{HF} / \mathrm{HCl}$ mixture $(1: 1: 3)$ and the solution analyzed on a Varian $715-\mathrm{ES}$ apparatus.

The determination of the Higher Heating Value (HHV) was carried out at the analytic division of the Institute "Instituto de Carboquímica" of the CSIC in Zaragoza following method UNE-EN 14918.

\section{Treatments for lowering the ash content}

For the chemical ash treatments two different hydrochar samples were considered. The first one possessed a considerable silicon and aluminum content in the ashes and the second one did not (Table 1). For both samples the predominant element in the ashes was calcium.

Table 1. Properties of hydrochar samples employed for the ash reduction treatment.

\begin{tabular}{|c|c|c|c|c|}
\hline & Elemental an & $(d$ & bon $^{\mathrm{a}}$ & \\
\hline h content & $\mathrm{H}$ & IV & $\mathrm{S}$ & $\mathrm{CaO}$ \\
\hline
\end{tabular}

\begin{tabular}{ccccccccc} 
Sample & {$[\mathrm{wt} \%]$} & {$[\mathrm{wt} \%]$} & {$[\mathrm{wt} \%]$} & {$[\mathrm{wt} \%]$} & {$[\mathrm{wt} \%]$} & {$[\mathrm{wt} \%]$} & {$[\mathrm{wt} \%]$} & {$[\mathrm{wt} \%]$} \\
\hline HTC-1 & 12.1 & 62.6 & 6.0 & 1.7 & 0.0 & 37.0 & 28.3 & 6.5 \\
HTC-2 & 16.9 & 55.7 & 6.2 & 2.3 & 1.3 & 55.1 & 4.6 & 1.0
\end{tabular}

${ }^{\mathrm{a}}$ Values on a dry and ash free basis.

The TR-BA (base-acid) procedure was adapted from the "Clean Coal Process" developed by Brooks et al. and involves two main steps: a caustic digestion and acid soaking. ${ }^{32}$ For all experimental studies the hydrochar sample HTC-1 was milled in a planetary ball mill to a particle size $<0.2 \mathrm{~mm}$. In a caustic digestion stage the hydrochar sample (4.0 g) was added to an aqueous $\mathrm{NaOH}$ solution $(10 \mathrm{~mL}, 15 \mathrm{wt} \%)$ placed in a stainless-steel autoclave and heated to the reaction temperature $\left(100-225^{\circ} \mathrm{C}\right)$. The mixture was stirred for 20 minutes under autogenous pressure. For separation of the solid from the liquid phase the reaction mixture was centrifuged and decanted or filtered. The solid was washed with water until reaching a neutral $\mathrm{pH}$. Then the solid was dried at $100{ }^{\circ} \mathrm{C}$ for $12 \mathrm{~h}$. The liquid phase was treated adding $\mathrm{H}_{2} \mathrm{SO}_{4}(98 \%$; to 
approx. $\mathrm{pH}$ 1) under stirring until a solid precipitated. The latter was filtered off and washed with water until reaching a neutral $\mathrm{pH}$. Then the solid was dried at $100{ }^{\circ} \mathrm{C}$ for 12 h. Both solids were joined and used together in the acid soaking. The solid was dispersed into water and treated adding $\mathrm{H}_{2} \mathrm{SO}_{4}$ (98\%; until a pH of 1.0). The mixture was stirred for $1 \mathrm{~h}$ at room temperature. Then, the solid was filtered off and washed with water until reaching a neutral $\mathrm{pH}$. The solid was dried and analyzed for its ash content.

In the acid treatment, i.e. $T R$ - $A$, hydrochar HTC-2 was dispersed in water and treated adding $\mathrm{H}_{2} \mathrm{SO}_{4}$ (98\%; until a pH of 1.0). The mixture was stirred for $2 \mathrm{~h}$ at $100{ }^{\circ} \mathrm{C}$. Then, the solid was filtered off and washed with water until reaching a neutral $\mathrm{pH}$. The solid was dried and analyzed for its ash content. When other acids were employed, i.e. $\mathrm{HCl}$, $\mathrm{HNO}_{3}$, acetic acid, or citric acid, the same amount in mol was used as for $\mathrm{H}_{2} \mathrm{SO}_{4}$.

\section{Up-grading process for the monoterpene mixture}

Catalysts employed for the dehydrogenation of the monoterpene mixture to paracymene were synthesized by incipient wetness impregnation. Metal precursor, i.e. $\mathrm{Pd}(\mathrm{OAc})_{2}$ and $\mathrm{Pt}(\mathrm{acac})_{2}$, were dissolved in the corresponding amount of toluene to achieve a final metal content of $1 \mathrm{wt} \%$. After impregnation of the support $(0.4-0.8$ $\mathrm{mm}$ ), the material was dried in an oven at $100{ }^{\circ} \mathrm{C}$ overnight. The catalysts were introduced into the reactor tube $(6.4 \mathrm{~mm}, 20 \mathrm{~cm}$, together with $1.0 \mathrm{~g}$ of $\mathrm{SiC})$ and used without any further activation treatment.

As feed a monoterpene mixture, distilled from the crude oil, was employed with a composition as displayed in Eq. 1. The feed was passed with a flow rate of $4 \mathrm{~mL} / \mathrm{h}$ at atmospheric pressure together with a carrier gas $(50-60 \mathrm{~mL} / \mathrm{h})$, either nitrogen or hydrogen. As the minimum reaction temperature was $200{ }^{\circ} \mathrm{C}$ and the boiling point of the mixture in the range of $170-180^{\circ} \mathrm{C}$, it is assumed that the reaction occurred in the gas phase.

Product composition is determined off-line by GC and GC-MS on HP-5 columns. Side products detected were partly or completely hydrogenated compounds such as paramenthenes and para-menthane and, in traces, para-cymenene.

\section{Results and discussion}

For the pilot plant trials four different end of chain biomass feedstocks were chosen: two different types of organic fraction of municipal solid (OFMSW-1 and OFMSW-2), 
orange peel waste (OPW) and the residues of a pepper plantation (PEP). More details on the source and properties of the biomass are provided in the Electronic Supplementary Information (ESI).

Up to $10 \mathrm{t}$ of wet biomass for each feedstock were processed at 200 to $210{ }^{\circ} \mathrm{C}$. The exact amounts processed and the characterization results for each feedstock are presented in Table 2. It can be seen that the HTC is very flexible since humidity contents over a wide range from 14 to $84 \%$ could be accepted. For the low humidity contents, process water was recycled to the reactor together with the feed, employing a final feeding humidity of 60 to $80 \%$. Ash content varied significantly from 5 to over $30 \%$. In contrast, carbon content and higher heating values (HHV) were similar with 45 to $50 \%$ and 17 to $18 \mathrm{MJ} / \mathrm{kgDM}$, respectively.

Table 2. Amount and properties of the biomass processed in the Pilot Plant.

\begin{tabular}{cccccccc} 
Entry & Biomass & $\begin{array}{c}\text { Wet } \\
\text { weight }\end{array}$ & Humidity & $\begin{array}{c}\text { Dry } \\
\text { weight }\end{array}$ & $\begin{array}{c}\text { Ash } \\
\text { content }^{\mathrm{a}}\end{array}$ & $\begin{array}{c}\text { C- } \\
\text { content }^{\mathrm{b}}\end{array}$ & HHV $^{\mathrm{c}}$ \\
\hline 1 & OFMSW-1 & 8425 & 34 & 5524 & 32.7 & 49.8 & $\mathrm{~d}$ \\
{$\left[\begin{array}{c}{[\mathrm{kg}]} \\
{[\%]}\end{array}\right.$} & OFMSW-2 & 7540 & 59 & 3093 & 24.7 & n.d. ${ }^{\mathrm{e}}$ & 16.7 \\
3 & OPW & 12250 & 84 & 1960 & 4.8 & 47.9 & 18.4 \\
4 & PEP & 3760 & 14 & 3220 & 14.0 & 45.5 & n.d. \\
\hline
\end{tabular}

${ }^{a}$ Ash content of the biomass, based on dry matter. ${ }^{\mathrm{b}}$ Carbon content on a dry and ashfree base. ${ }^{\mathrm{c}}$ Higher heating value in MJ per kg of dry matter. ${ }^{\mathrm{d}}$ Impossible to determine since sample did not burn in the autoclave. ${ }^{\mathrm{e}}$ Not determined.

After the HTC process with a residence time of 6 to $8 \mathrm{~h}$, hydrochar was obtained as product (Table 3) together with a solid inorganic fraction (mixture of sand, stones and hydrochar) and gases (Table 4). Additionally, organic and inorganic components are dissolved in the process water which will not be taken into account in this study. The yield of hydrochar was between 47 and 59\% (Table 3) for OFMSW and PEP. In the case of OPW the yield was significantly lower which was, probably, caused by the morphology of the carbon. The very soft orange peels formed small carbon particles $(<$ $1 \mathrm{~mm}$ diameter) which sedimented in different parts of the plant so that the hydrochar 
produced could not be collected quantitatively. However, this issue should be solved easily by improvement of the engineering design of the plant and should be less problematic during long-term operation. On the other hand, the OPW feedstock is a suitable biomass to demonstrate the efficiency of the HTC process. Hence, carbon content is concentrated from $47.9 \%$ (Table 2, entry 3) to 63.8\% (Table 3, entry 3) and HHV from 18.4 to $24.5 \mathrm{MJ} / \mathrm{kgDM}$. Similar observation can be made for the other three feedstocks, although the effect is less pronounced in these cases. The carbon content is raised at least eight to ten percentage points. The increase of the HHV is masked by the high ash content of the corresponding hydrochar. When the HHV is compared on a dry and ash-free base, it can be seen that the value is approximately $25 \mathrm{MJ} / \mathrm{kg}$ for all four hydrochars produced. Hence, hydrochar should be very suitable as solid fuel which can be transported efficiently due to its energy density. However, ash content is crucial for this application. Furthermore, as already stated above, for domestic use the ash content of non-woody pellets is limited to $10 \%$ (EN ISO 17225-6) which is only met for one of the four products.

Table 3. Amount and properties of the hydrochar obtained in the Pilot Plant trials.

\begin{tabular}{cccccccc} 
& Biomass & Hydrochar $^{\mathrm{a}}$ & Yield $^{\mathrm{b}}$ & Ash content $^{\mathrm{c}}$ & C-content $^{\mathrm{d}}$ & HHV $^{\mathrm{e}}$ & HHV $^{\mathrm{f}}$ \\
\hline Entry & feedstock & {$[\mathrm{kg}]$} & {$[\%]$} & {$[\% \mathrm{DM}]$} & {$[\%$ DAF $]$} & {$[\mathrm{MJ} / \mathrm{kgDM}]$} & {$[\mathrm{MJ} / \mathrm{kgDAF}]$} \\
\hline 1 & OFMSW-1 & 3240 & 58.7 & $10.7-31.1$ & 58.4 & 19.5 & 25.4 \\
2 & OFMSW-2 & 1447 & 46.8 & $21.3-35.8$ & 60.2 & 18.8 & 25.2 \\
3 & OPW & 723 & 37.3 & $3.2-6.8$ & 63.8 & 24.5 & 25.7 \\
4 & PEP & 1726 & 53.6 & $11.4-19.7$ & 55.7 & 19.6 & 24.4 \\
\hline
\end{tabular}

${ }^{a}$ Hydrochar product from the HTC process. ${ }^{b}$ Mass yield of dry hydrochar referred to biomass dry matter. ${ }^{c}$ Ash content of the hydrochar, based on dry matter; for detailed information on the composition of the ashes see ESI. ${ }^{d}$ Carbon content on a dry and ashfree base. ${ }^{\mathrm{e}}$ Higher heating value in MJ per kg of dry matter. ${ }^{\mathrm{f}}$ Higher heating value in MJ per kg on a dry and ash-free base.

The hydrochar discussed before is considered the most important product of the HTC process and its application as solid fuel is straightforward. In addition to this, inorganics or inorganics/hydrochar mixtures and gases were obtained as products. Amounts and 
composition highly depended on the biomass feedstock (Table 4). For the high ash OFMSW feedstocks inorganic material was separated with $10 \%$ mass yield which might be employed for soil amelioration in combination with carbon sequestration. Gases evolved from the top of the reactor with 2 to $13 \%$ yield being carbon dioxide the main component with over $95 \%$.

Table 4. Amount and properties of additional products obtained in the Pilot Plant trials.

\begin{tabular}{|c|c|c|c|c|c|c|c|c|}
\hline \multirow[b]{3}{*}{ Entry } & \multirow[b]{2}{*}{ Biomass } & \multicolumn{2}{|c|}{ High inorganic hydrochar ${ }^{\mathrm{a}}$} & \multirow[b]{2}{*}{ Inorganics $^{\mathrm{d}}$} & \multirow{2}{*}{$\begin{array}{l}\mathrm{Gas}^{\mathrm{e}} \\
\text { Yield }\end{array}$} & \multicolumn{3}{|c|}{ Gas composition } \\
\hline & & Yield $^{\mathrm{b}}$ & Ash content ${ }^{\mathrm{c}}$ & & & $\mathrm{CO}_{2}$ & $\mathrm{CO}$ & Other \\
\hline & feedstock & {$[\%]$} & {$[\% \mathrm{DM}]$} & {$[\%]$} & {$[\%]$} & {$[\%]$} & {$[\%]$} & {$[\%]$} \\
\hline 1 & OFMSW-1 & 13.1 & 74.3 & -- & 2.4 & 95.1 & 1.3 & 3.6 \\
\hline 2 & OFMSW-2 & 3.8 & 38.5 & 6.3 & 7.4 & 97.4 & 1.6 & 1.0 \\
\hline 3 & OPW & -- & -- & -- & 12.5 & n.d. & n.d. & n.d. \\
\hline 4 & PEP & -- & -- & 3.2 & 4.5 & 97.2 & 1.3 & 1.5 \\
\hline
\end{tabular}

${ }^{a}$ Hydrochar with a high inorganic content which was separated in the post-treatment facility due to higher density: sand and stones covered by hydrochar. ${ }^{b}$ Mass yield of dry material referred to biomass dry matter. ${ }^{\mathrm{c}}$ Based on dry matter. ${ }^{\mathrm{d}}$ Inorganic material such as metals, big stones, broken glass, etc. ${ }^{\mathrm{e}}$ Gas evolved from the top of the HTC reactor.

In the pilot plant, energy consumptions have been measured. As it is assumed that operation can be further optimized, the values obtained have to be considered as maximum values not as average values for plant operation. Main electrical energy consumer is the pumping process which introduces the biomass feedstock into the reactor. Under optimal reaction conditions with humidity contents from 60 to $80 \%$, feeding rates from 100 to $200 \mathrm{~kg} / \mathrm{h}$ were achieved. In this case, electrical energy consumption for the whole carbonization process can be assumed to be between 100 and $150 \mathrm{kWh}$ per ton of dry biomass.

Thermal energy is required for heating the reactor to reaction temperature and, therewith, for allowing the hydrothermal carbonization to occur. This value oscillated considerably during the NEWAPP trials since many factors have to be taken into 
account. The average range was from 3600 to $4900 \mathrm{MJ} / \mathrm{kg}$. Although the numbers are still far from being optimized, they show already that during the HTC process net energy is produced since hydrochar contains more energy than the energy consumed during the process. Therefore, in a first approximation, $25 \%$ to $35 \%$ of the inherent energy of the hydrochar is required for process heat and electrical energy in the case of the OFMSW feedstocks.

As summary, it can be stated that all four biomass feedstocks are suitable for the HTC process. Carbon content and HHV indicate that carbon and energy are concentrated in the solid. For the use of hydrochar the ash content is the most crucial property. Ash separation by physical methods is promising and can solve this issue in many cases. Chemical extraction is also an alternative as it is shown in the following.

\section{Ash reduction treatments}

When carbon is burned to valorize its inherent energy the different chemical elements suffer diverse transformations depending on their nature. The organic part is converted into carbon dioxide and water. Heteroatoms like nitrogen and sulfur are oxidized to inorganic gases which then form acids in contact with water. Inorganic elements such as alkali-earth metals, transition metals, aluminum and silicon are mineralized to their oxides and remain in the ashes.

When regarding hydrochar, the composition of the inorganic content depends on two main factors, first on the initial composition of the inorganic matter in the raw material and second, on the chemical behavior of these elements during the process. The inorganic matter of hydrochar is the part which is not dissolved during the carbonization process. For instance, calcium and silicon remain in the solid reaction product whereas potassium is easily dissolved. With respect to the initial composition of the inorganic part, there are two distinct sources for this matter. Inorganic elements such as potassium or calcium are common plant components and are introduced incorporated into the raw material. In contrast, soil and dust are brought in the process by contaminations of the raw materials. The contaminants are often a source of silicon, aluminum and calcium. The composition of the inorganic material is of a special importance when chemical ash reduction treatments have to be taken into account.

When the valorization of hydrochar as solid fuel is foreseen specifications of EN ISO 17225-6 should be taken into account which limits the ash content to 5 or $10 \mathrm{wt} \%$. 
However, in many cases these limits are not met, as explained before either due to the composition of the plant material or caused by contaminations. Therefore, ash reduction post treatments were contemplated to circumvent this issue.

Having in mind the solubility of different elements, two types of hydrochars were selected in this study: one with considerable silicon content, HTC-1, and another without, HTC-2 (Table 1). Both possessed calcium as main element of the ashes since this is the case for most lignocellulose derived hydrochars, as it has been observed in the pilot plant trials.

For each hydrochar sample a suitable treatment was designed. For the silicon rich material the procedure was adapted from a literature process developed for decreasing the mineral content in fossil coal: the ultra clean carbon (UCC) process $^{32,33}$ and called herein treatment TR-BA (base-acid). It consists of a two step treatment: a basic treatment at $225^{\circ} \mathrm{C}$ followed by an acid treatment at room temperature. As the ash reduction treatment should be implemented into the HTC pilot plant process the temperature of the basic treatment should be adapted. The HTC process is currently carried out at temperatures between 200 and $210{ }^{\circ} \mathrm{C}$ the post-process treatment at $225^{\circ} \mathrm{C}$ would imply further energy consumption with a severe penalty on the whole energy balance of the HTC process. To avoid this, lower temperatures were studied for this step.

Hence, sample HTC-1 was treated by treatment TR-BA applying temperatures for the initial basic treatment between 100 and $225^{\circ} \mathrm{C}$. After the first step, the recovered solid is submitted to a treatment with sulfuric acid at room temperature. The results are summarized in Table 5. It can be seen that the mass balance for the solid material decreased from approximately $80 \mathrm{wt} \%$ obtained at temperatures between 100 and 150 ${ }^{\circ} \mathrm{C}$ to 65 and $55 \mathrm{wt} \%$ at 180 and $225{ }^{\circ} \mathrm{C}$, respectively. The carbon content remains constant at $63 \%$ up to $150{ }^{\circ} \mathrm{C}$ (on dry and ash-free base, Table 5, entries 2 to 4). At higher temperatures the carbon content is increased to $66 \mathrm{wt} \%\left(180^{\circ} \mathrm{C}\right.$, Table 5 , entry 5$)$ and almost $69 \mathrm{w} \%\left(225^{\circ} \mathrm{C}\right.$, Table 5, entry 6).

The total ash content was reduced for the whole temperature range after the treatment TR-BA. At 120, 150 and $225^{\circ} \mathrm{C}$, the final ash content was between 4 and $5 \mathrm{wt} \%$. Different effects were observed for the cations. For the Ca-content in the ashes a clear tendency was observed: it decreased successively when increasing reaction temperature of the basic treatment. The silicon content in the ashes increased successively to $66 \mathrm{wt} \%$ upon treatments at increasing temperatures up to $180^{\circ} \mathrm{C}$ (Table 5, entry 5). Only at 225 
${ }^{\circ} \mathrm{C}$ this value was reduced to $15 \mathrm{wt} \%$ (Table 5, entry 6). Similarly, the aluminum content is higher than the initial one after treatment at temperatures up to $180^{\circ} \mathrm{C}$. Again, at 225 ${ }^{\circ} \mathrm{C}$, it decreased to $2.5 \mathrm{wt} \%$ (entry 6 ).

Table 5. Properties of hydrochar samples obtained with the ash reduction treatment TRBA. For details on the procedure see experimental part.

\begin{tabular}{|c|c|c|c|c|c|c|c|}
\hline \multirow[b]{3}{*}{ entry } & \multirow{3}{*}{$\begin{array}{l}\text { temp. basic } \\
\text { treatment }^{\mathrm{a}} \\
{\left[{ }^{\mathrm{o}} \mathrm{C}\right]}\end{array}$} & \multirow{3}{*}{$\begin{array}{c}\text { mass } \\
\text { balance } \\
{[\%]}\end{array}$} & \multirow{3}{*}{$\begin{array}{c}\text { EA }(\mathrm{DAF})^{\mathrm{b}} \\
\mathrm{C} \\
{[\mathrm{wt} \%]}\end{array}$} & \multirow{3}{*}{$\begin{array}{c}\text { ash } \\
\text { content }^{\mathrm{c}} \\
{[\mathrm{wt} \%]}\end{array}$} & \multicolumn{3}{|c|}{ Ash composition } \\
\hline & & & & & $\mathrm{CaO}$ & $\mathrm{SiO}_{2}$ & $\mathrm{Al}_{2} \mathrm{O}_{3}$ \\
\hline & & & & & [wt\%] & [wt $\%]$ & [wt $\%]$ \\
\hline 1 & --- & --- & 62.6 & $12.1(100)$ & 37.0 & 28.3 & 6.5 \\
\hline 2 & 100 & 79.0 & 62.6 & $10.2(67)$ & 19.2 & 44.5 & 8.8 \\
\hline 3 & 120 & 83.2 & 62.7 & $4.60(31)$ & 18.1 & 47.3 & 11.9 \\
\hline 4 & 150 & 77.7 & 62.5 & $4.04(26)$ & 8.2 & 59.7 & 14.2 \\
\hline 5 & 180 & 65.0 & 65.9 & $6.47(35)$ & 6.8 & 66.5 & 12.7 \\
\hline 6 & 225 & 55.0 & 68.5 & $4.60(21)$ & 1.9 & 15.3 & 2.5 \\
\hline
\end{tabular}

${ }^{a}$ Temperature of the basic treatment of the basic-acidic treatment. ${ }^{b}$ Values from elemental analysis; expressed on a dry and ash free basis. ${ }^{c}$ In parenthesis the values are given as percentage the initial ash amount; value $=(($ ash content in $\% *$ mass balance in $\%) /$ initial ash content in \%).

At first glance several of the values presented in Table 5 do not seem to be coherent. However, detailed analysis reveals three trends which explain the experimental data in the main. First, a process similar to the HTC process proceeds at temperatures of $180{ }^{\circ} \mathrm{C}$ and higher. This is manifested in the decrease of the mass balance at these temperatures (Table 5, entries 5 and 6). The mass loss is mainly due to chemical dehydration decreasing oxygen content and increasing the carbon content. Second, silicon oxide is only dissolved efficiently at $225^{\circ} \mathrm{C}$. This result is perfectly in accordance with literature which reports that a temperature of $250{ }^{\circ} \mathrm{C}$ is required for the transformation of silicon oxide and clays into alkali silicates and alumino-silicates. ${ }^{34}$ Hence, due to the decreasing ash content and the decreasing mass balance on one hand and the insolubility of this element on the other hand, its concentration in the ashes increased until a temperature of 
$180{ }^{\circ} \mathrm{C}$ for the basic treatment. A similar effect was observed for aluminum for the same reasons. The only difference is the temperature at which this element gets dissolved which is $180{ }^{\circ} \mathrm{C}$ instead of $225{ }^{\circ} \mathrm{C}$. Third, calcium oxide is dissolved better with increasing temperature. Combing the three effects the trends observed for carbon content, ash content and ash composition could be explained. Even due to a lower mass balance the ash content can increase at higher temperature (as observed), although the value obtained for the treatment at $180{ }^{\circ} \mathrm{C}$ should still be a bit lower.

The main conclusion which can be drawn from this experimental series is that for an efficient reduction of highly insoluble oxides such as silicon and aluminum oxide the treatment temperature should be higher than $200{ }^{\circ} \mathrm{C}$, i.e. even higher than the HTC process itself. Therefore, the energetic penalty is considerable and might be acceptable for cases in which high value added materials of high purity could be produced. However, in the case of solid fuels an alternative solution should be found. On the other hand, ash content was reduced at temperatures of around $150{ }^{\circ} \mathrm{C}$ to below the target value of $5 \mathrm{wt} \%$. Therefore, it can be concluded that a harsh treatment is not necessary to fulfill the limits of EN ISO 17225-6 and the procedure should be optimized and simplified with the aim to dissolve predominantly the more soluble oxides such as calcium oxide. This was attempted with the treatment TR-A which will be described below.

With the same criteria as for treatment TR-BA, i.e. the compatibility with the current HTC process, the acid treatment TR-A was developed for the second hydrochar sample, HTC-2. For the treatment TR-A a reaction temperature and time of $100{ }^{\circ} \mathrm{C}$ and $2 \mathrm{~h}$ were selected, respectively. Under these conditions five acids were tested, i.e. sulfuric acid, hydrochloric acid, nitric acid, acetic acid and citric acid. The results are summarized in Table 6. The mass balance varied between 74 and $86 \%$ and losses should be due to working on small lab-scale. Only in the case of sulfuric acid the mass balance is lower with only $68 \%$ (Table 6, entry 2). The carbon amount observed by elemental analysis remained constant for the four cases, again with the exception of the treatment with sulfuric acid. Here, a slight increase from 56 to $59 \mathrm{wt} \%$ was detected. The ash reduction manifested in the remaining ash content was different when employing the different acids. The treatment with sulfuric acid reduced the ash content to approximately one tenth of the original value (Table 6, entry 2). Hydrochloric acid was also quite effective and reduced the initial $17 \mathrm{wt} \%$ to only $6 \mathrm{wt} \%$ (Table 6 , entry 3). The other three acids, 
nitric, acetic and citric acid, were less efficient and reduced the ash content only moderately to 10 to $11 \mathrm{wt} \%$ (Table 6, entries 4-6).

The ash composition was changed significantly by the sulfuric acid treatment. The calcium oxide content was decreased to below $10 \mathrm{wt} \%$ (of the ash) whereas the concentration of silicon and aluminum oxide increased to 58 and $10 \mathrm{wt} \%$, respectively (Table 6, entry 1). The same trends, in a less pronounced manner, were observed for the treatment with hydrochloric acid. For the three remaining acids the effects were similar but even weaker.

Table 6. Properties of hydrochar samples obtained with the ash reduction treatment TRA employing different acids at $100^{\circ} \mathrm{C}$ for $2 \mathrm{~h}$.

\begin{tabular}{cccccccc} 
& & mass & Elem. Aanalysis & ash & \multicolumn{3}{c}{ Ash composition } \\
\cline { 5 - 8 } entry & acid & balance & $\mathrm{C}$ & content & $\mathrm{CaO}$ & $\mathrm{SiO}_{2}$ & $\mathrm{Al}_{2} \mathrm{O}_{3}$ \\
\hline 1 & {$\left[{ }^{\circ} \mathrm{C}\right]$} & {$[\%]$} & {$[\% \mathrm{DAF}]^{\mathrm{a}}$} & {$[\mathrm{wt} \%]$} & {$[\mathrm{wt} \%]$} & {$[\mathrm{wt} \%]$} & {$[\mathrm{wt} \%]$} \\
\hline 2 & --- & --- & 55.7 & 16.9 & 55.1 & 4.6 & 1.0 \\
3 & $\mathrm{H}_{2} \mathrm{SO}_{4}$ & 68.2 & 58.5 & 1.5 & 7.3 & 58.4 & 10.3 \\
4 & $\mathrm{HCl}^{2}$ & 78.1 & 55.7 & 6.3 & 29.6 & 28.6 & 3.8 \\
5 & $\mathrm{HNO}_{3}$ & 86.1 & 54.8 & 11.1 & 44.2 & 19.6 & 2.4 \\
6 & $\mathrm{AcOH}$ & 78.1 & 55.2 & 10.2 & 62.6 & 17.5 & 3.1 \\
\hline
\end{tabular}

${ }^{a}$ Values from elemental analysis; expressed on a dry and ash free basis.

Three conclusions can be drawn from these experimental data. First of all, the sulfuric acid treatment still causes chemical dehydration, and carbonization of the biomass proceeds further. Due to the severity of the treatment characterized by the strong acidity, oxygen is eliminated as water and the carbon content slightly increased. Secondly, under the present conditions sulfuric acid dissolves efficiently the inorganic matter of the hydrochar. Hence, calcium concentration is strongly decreased whereas silicon and aluminum oxides are mere spectators. As the total amount of ash is decreased their concentration increases nominally. Both actions, dehydration and ash reduction also decrease the mass balance in the sulfuric acid treatment. Thirdly, 
hydrochloric acid acts not as powerful as sulfuric acid but might still be an interesting alternative. With this acid the ash content is reduced to less than half of the initial content, although with a value of $6 \mathrm{wt} \%$ for the final ash content, the lower ash value of EN ISO 17225-6 (5 wt \%) is not met. However, the increase of the acid concentration should improve this result so that very similar effects should be observed on mass balance, carbon content and ash content for hydrochloric acid as for sulfuric acid. The treatments with nitric acid, acetic acid and citric acid were not found to be useful.

As the temperature of the acidic treatment is lower as the reaction temperature, i.e. 100 versus of $200{ }^{\circ} \mathrm{C}$, the incorporation of a chemical ash-reduction with sulfuric acid is straightforward. At the exit of the pressure reactor the hot hydrochar water slurry can be mixed with cold sulfuric acid and maintained for the desired reaction time. Hence, this is a valid option to fulfill the ash limits of EN ISO 17225-6. However, when sustainability is concerned, gravimetric separation of inorganics is preferred since the extraction process produces salts. Furthermore, the avoidance of contamination of the biomass feedstock would be the "cleanest procedure" to lower the ash content.

\section{Liquid organic effluents and their up-grading}

At the pilot plant, generation of an additional product stream, i.e. an organic liquid, was observed for certain feedstocks. The best yield was obtained for OPW, whereas the yield of the oil with other feedstocks was almost negligible. The oil is extracted together with steam from the top of the reactor and separated from condensates (mainly water) spontaneously. In general, the steam extraction is part of the plant's pressure and temperature control unit and is used for process control in the reactor. ${ }^{35}$

The amount of the organic liquid was quantified when the plant reached a steady operation phase. Thereby, $38.2 \mathrm{~kg}$ were obtained from $7456 \mathrm{~kg}$ of wet biomass with $84 \%$ humidity. The main components of this liquid were monoterpenes in the ratio indicated in Eq. 1.

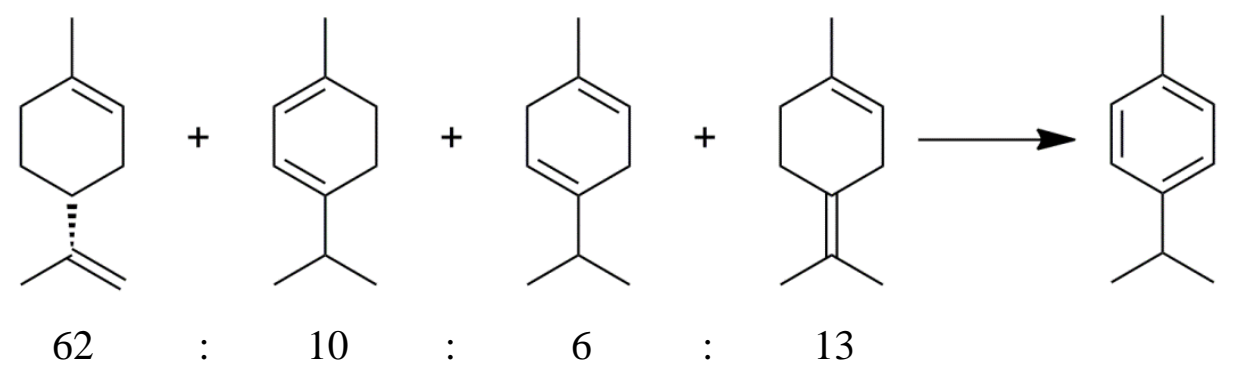


It is well known in literature that limonene can be isomerized into $\alpha$-terpinene, $\gamma$ terpinene and terpinolene. ${ }^{36-41}$ Therefore, it is concluded that the limonene incorporated in the orange peel waste is isomerized under reaction conditions or during the separation step. Then, $35.2 \mathrm{~kg}$ of partly isomerized limonene was obtained from $1192 \mathrm{~kg}$ of dry matter which corresponds to a mass yield of $2.95 \%$. This is quite a high yield when considering that in the laboratory the maximum yield obtained was $5 \%$ citrus waste by supercritical carbon dioxide extraction, ${ }^{22}$ although the theoretical yield might be lower in the present case due to a different biomass feedstock. Therefore, it is concluded that the HTC process is very suitable for extraction of hydrophobic compounds included in biomass waste feedstock since biomass is degraded and the chemicals can diffuse out.

The mixture of monoterpenes might find industrial applications e.g. as industrial solvent as oil-rig cleaning agent or floating degreaser. ${ }^{21}$ It has a high solvent power for degreasing and lower volatility which might also be an advantage with respect to environmental concerns. Solvent properties of limonene favor it as substitute for halogenated or aromatic (xylene, toluene) solvents. ${ }^{21}$

Limonene is also consumed in fragrance industry. However, to fulfill the purity requirements the monoterpene mixture has to be distilled and separated into its components. To avoid this, the conversion of the whole mixture into the value-added fragrance compound para-cymene is envisaged (Eq. 1).

In literature, many examples can be found to convert pure limonene into para-cymene. Quantitative yield was achieved in the conversion with ethylenediamine, anhydrous $\mathrm{FeCl}_{3}$ and sodium. ${ }^{42}$ Catalytic methods in batch mode are reported with metalcontaining sepiolite and microwave heating ${ }^{43}$ or in the presence of $\mathrm{Pd} / \mathrm{C},{ }^{22}$ as well as in continuous flow reactor with $\mathrm{Pd} / \mathrm{C},{ }^{44}$ solution-synthesized AuPd nanoparticles ${ }^{45}$ or simply $\mathrm{TiO}_{2}{ }^{46}$

For the up-grading of the monoterpene mixture, metal supported catalysts and a continuous flow reactor were chosen. Hence, $\mathrm{Pd}$ and Pt precursors were impregnated on active carbon (C) and alumina $\left(\mathrm{Al}_{2} \mathrm{O}_{3}\right)$ as supports and examined in nitrogen and hydrogen atmosphere. The $\mathrm{Pd} / \mathrm{C}$ catalyst was used to establish the reaction temperature. It was found that in the temperature range from 200 to $320^{\circ} \mathrm{C}$, conversion improved successively and almost full conversion was observed at the highest temperature (Figure 2 ). Therefore, all catalysts were tested at this temperature under nitrogen and hydrogen atmosphere. 
Figure 1. Dehydrogenation of the monoterpene mixture to para-cymene over $\mathrm{Pd} / \mathrm{C}$ in nitrogen atmosphere in the temperature range from 200 to $320^{\circ} \mathrm{C}$.

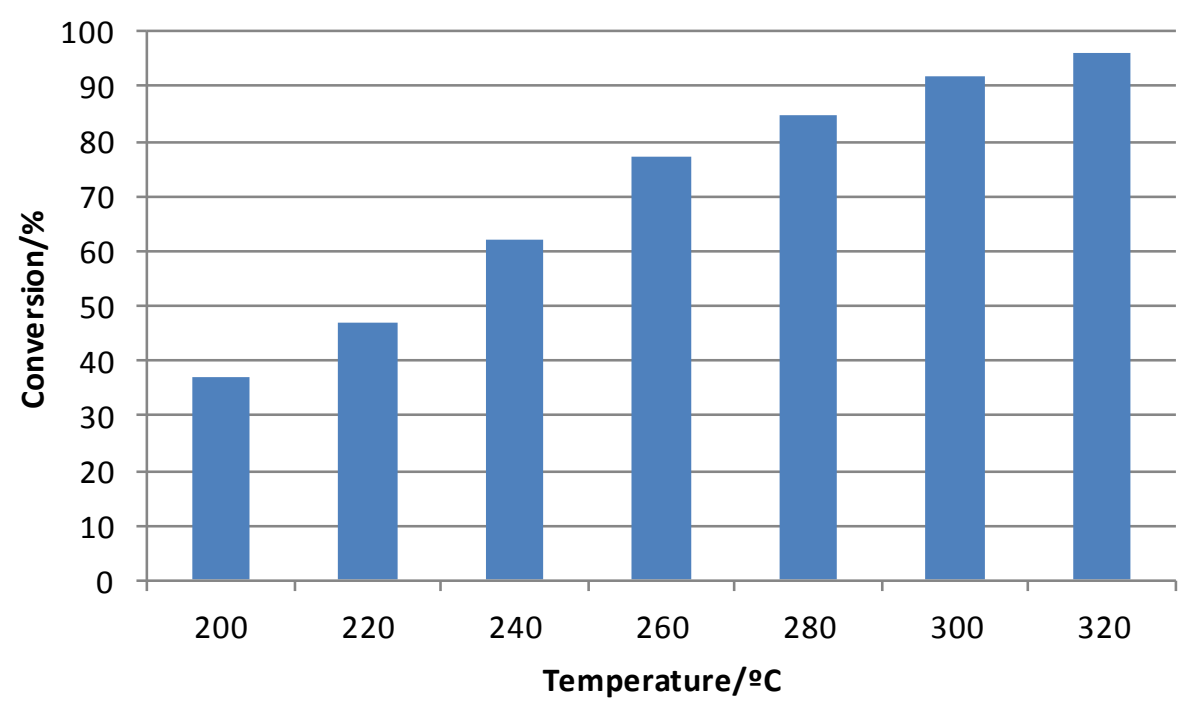

In Figure 2 conversions and yields of para-cymene are displayed. It can be seen that para-cymene can be obtained in almost quantitative yield, e.g. with $\mathrm{Pd} / \mathrm{C}$ in nitrogen atmosphere, but the catalyst deactivation is an issue at longer time on stream. Alumina as support for Pd is less suitable since strong deactivation was detected almost at the beginning of the reaction. Hydrogen atmosphere helps to mitigate catalyst deactivation. However, partial hydrogenation occurred which lowered the yield of the desired product already at the beginning. Palladium on $\mathrm{C}$ has a better stability with time on stream than $\mathrm{Pt} / \mathrm{C}$. For further information on the exact product composition see Table S3 in the ESI. From the dehydrogenation study it can be concluded that the up-grading of the monoterpene mixture to para-cymene is a valuable option. Reaction conditions have to be further optimized to assure also economical viability. 
Figure 2. Conversions of the monoterpene mixture and yield of para-cymene for the dehydrogenation experiments with different catalysts at $320{ }^{\circ} \mathrm{C}$.

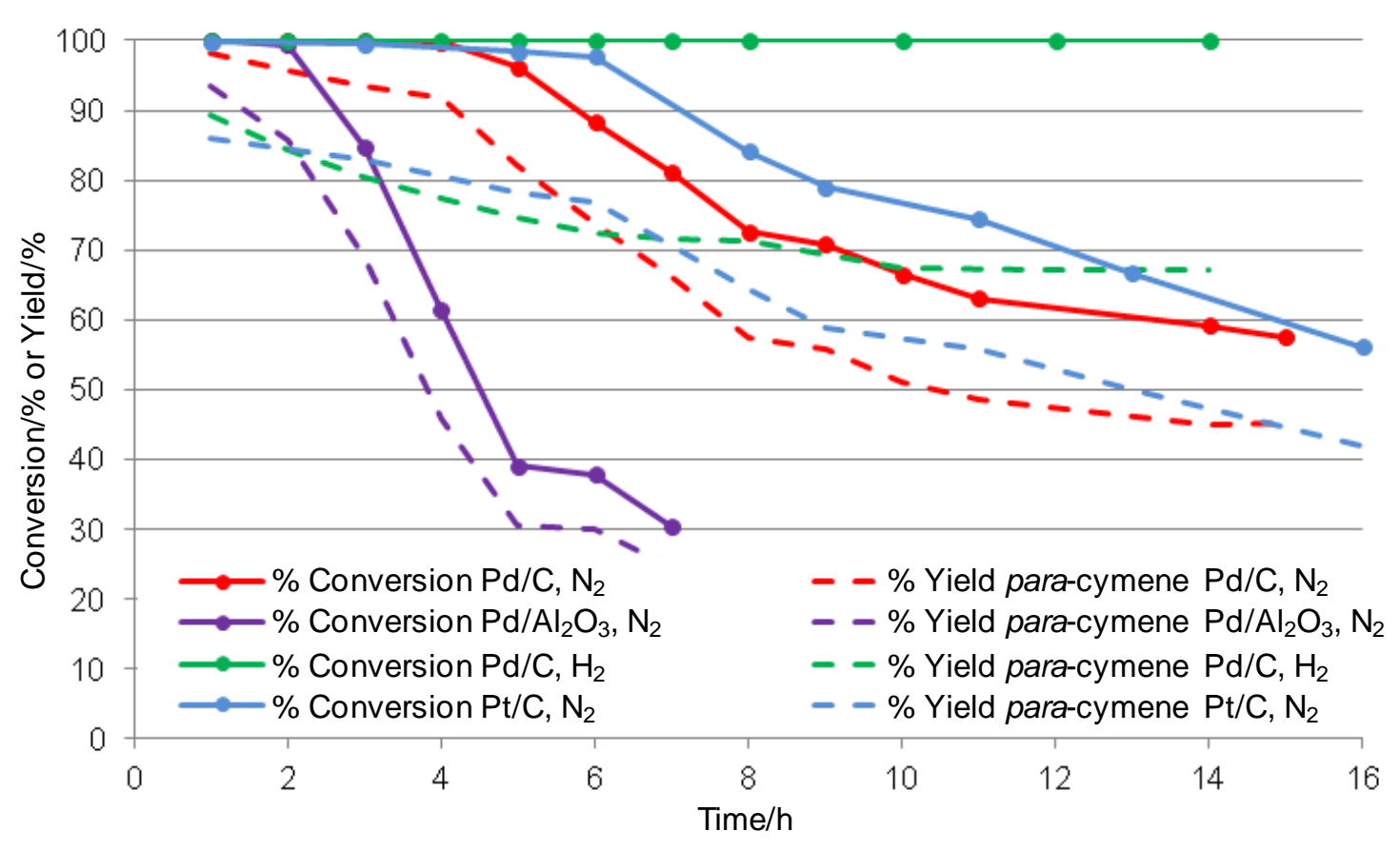

\section{Conclusions}

It has been shown that wet biomass feedstocks are interesting raw materials for fuels and chemicals. First treated by hydrothermal carbonization a solid fuel is obtained. The ash content has to be monitored carefully. For the use as domestic solid fuel it should be below 10\% (see e.g. EN ISO 17225-6). If the inorganic content cannot be avoided in the raw material, which would be the best option, ash content can be reduced by physical treatment or chemical extraction. Thereby, it was demonstrated that especially calcium can be extracted from hydrochar at $100{ }^{\circ} \mathrm{C}$ with sulfuric acid. This extraction can be combined with the HTC process at the reactor exit.

For some biomass feedstocks, e.g. orange peel waste, an organic liquid was obtained which consisted mainly of monoterpenes which can be used as industrial solvent. It was demonstrated that the mixture can also be up-graded to para-cymene, a value-added fragrant compound.

\section{Acknowledgement}

Authors are grateful for financial support from the EU (FP7-SME-2013-605178NEWAPP) and from the Spanish Ministry of Economy and Competitiveness (Innpacto 
Programme, IPT-2012-0023-120000). We thank our NEWAPP partners (http://newappproject.eu/en/partners.html), especially M. Ryberg and M. Owsianiak from the Technical University of Denmark (DTU) and L. Doyle from TTZ Bremerhaven, for fruitful discussions and valuable suggestions.

\section{References}

1. P. Zhao, Y. Shen, S. Ge, Z. Chen and K. Yoshikawa, Appl. Energ., 2014, 131, 345-367.

2. N. Y. Amponsah, M. Troldborg, B. Kington, I. Aalders and R. L. Hough, Renewable Sustainable Energy Rev., 2014, 39, 461-475.

3. S. Zinoviev, F. Müller-Langer, P. Das, N. Bertero, P. Fornasiero, M. Kaltschmitt, G. Centi and S. Miertus, ChemSusChem, 2010, 3, 1106-1133.

4. A. Herrmann, Bioenerg. Res., 2013, 6, 372-387.

5. C. Tricase and M. Lombardi, Biofuels, 2012, 3, 749-760.

6. L. A. Pfaltzgraff, M. De Bruyn, E. C. Cooper, V. Budarin and J. H. Clark, Green Chem., 2013, 15, 307-314.

7. J. S. Van Dyk, R. Gama, D. Morrison, S. Swart and B. I. Pletschke, Renewable Sustainable Energy Rev., 2013, 26, 521-531.

8. C. M. Galanakis, Trends Food Sci. Tech., 2012, 26, 68-87.

9. N. Mirabella, V. Castellani and S. Sala, J. Cleaner Prod., 2014, 65, 28-41.

10. N. Denek and A. Can, Small Ruminant Res., 2006, 65, 260-265.

11. E. Uçkun Kiran, A. P. Trzcinski, W. J. Ng and Y. Liu, Fuel, 2014, 134, 389-399.

12. P. García Herrera, M. C. Sánchez-Mata and M. Cámara, Innovative Food Sci. Emerg. Technol., 2010, 11, 707-711.

13. B. Digman and D. S. Kim, Environ. Prog., 2008, 27, 524-537.

14. A. I. Smeds, P. C. Eklund, R. E. Sjöholm, S. M. Willför, S. Nishibe, T. Deyama and B. R. Holmbom, J. Agric. Food. Chem., 2007, 55, 1337-1346.

15. K. Sundberg, B. R. Holmbom, C. Eckerman and M. Adams (Raisio Chemicals LTD), Method for recovering non-fibrous substances from wood material, WO 02/40767, 2002.

16. O. A. Simakova, E. V. Murzina, J. Wärnå and D. Y. Murzin, J. Mol. Catal. A: Chem., 2014, 388-389, 154-161.

17. R. Wikandari, H. Nguyen, R. Millati, C. Niklasson and M. J. Taherzadeh, Biomed. Res. Int., 2015, 2015, doi: 10.1155/2015/494182.

18. Q. Li, J. A. Siles and I. P. Thompson, Appl. Microbiol. Biotechnol., 2010, 88, 671-678.

19. J. Ángel Siles López, Q. Li and I. P. Thompson, Crit. Rev. Biotechnol., 2010, 30, 63-69.

20. d-limonene products, http://www.biochemcorp.com/dlimonene2.htm, (accessed 16/10/2015).

21. F. Kerton and R. Marriott, in Alternative Solvents for Green Chemistry, The Royal Society of Chemistry, 2013, DOI: 10.1039/9781849736824-00149, pp. 149-174.

22. J. H. Clark, E. M. Fitzpatrick, D. J. Macquarrie, L. A. Pfaltzgraff and J. Sherwood, Catal. Today, 2012, 190, 144-149.

23. L. P. Koh and J. Ghazoul, Biol. Conserv., 2008, 141, 2450-2460. 
24. M. Ahmad, A. U. Rajapaksha, J. E. Lim, M. Zhang, N. Bolan, D. Mohan, M. Vithanage, S. S. Lee and Y. S. Ok, Chemosphere, 2014, 99, 19-33.

25. P. Tanger, J. L. Field, C. E. Jahn, M. W. DeFoort and J. E. Leach, Front. Plant Sci., 2013, 4, doi: 10.3389/fpls.2013.00218.

26. M. I. Jahirul, M. G. Rasul, A. A. Chowdhury and N. Ashwath, Energies, 2012, 5, 4952-5001.

27. M. M. Titirici, A. Thomas, S. H. Yu, J. O. Müller and M. Antonietti, Chem. Mater., 2007, 19, 4205-4212.

28. A. Salimbeni, Biobased Char Market Potentials, European Biomass Industry Association, 2015.

29. EN 14961

30. The norm EN ISO 17225 replaced the former one, i.e. EN 14961. Hydrochar is now explicitely excluded from this norm since it is thermally treated biomass. However, future specification for hydrochar as solid fuel should be similar.

31. A. Corma, M. Hitzl, F. Pomares and M. Renz, Catal. Today, 2015, 257, 154159.

32. P. Brooks, K. Clark, J. Langley, G. Lothringer and B. Waugh Process for desmineralising coal, WO 2004/039927 A1, 2003.

33. P. Meshram, B. K. Purohit, M. K. Sinha, S. K. Sahu and B. D. Pandey, Renewable Sustainable Energy Rev., 2015, 41, 745-761.

34. N. Wijaya and L. Zhang, Energy \& Fuels, 2011, 25, 1-16.

35. M. Hitzl, A. Corma and M. Renz (Ingelia S.L.), Method for Extracting Biochemical Products Obtained from a Process of Hydrothermal Carbonization of Biomass, WO 2012/168502, 2012.

36. D. Kaur, R. R. Setia, K. K. Chahal and B. R. Chhabra, Indian J. Chem., Sect B, 2011, 50, 611-614.

37. R. Rachwalik, M. Hunger and B. Sulikowski, Appl. Catal. A: Gen., 2012, 427428, 98-105.

38. J. Jiang, F. Gándara, Y.-B. Zhang, K. Na, O. M. Yaghi and W. G. Klemperer, J. Am. Chem. Soc., 2014, 136, 12844-12847.

39. N. Comelli, E. Ponzi and M. Ponzi, J. Am. Oil Chem. Soc., 2005, 82, 531-535.

40. C. Catrinescu, C. Fernandes, P. Castilho and C. Breen, Appl. Catal. A: Gen., 2006, 311, 172-184.

41. A. D. Stefanis, G. Perez, O. Ursini and A. A. G. Tomlinson, Appl. Catal. A: Gen., 1995, 132, 353-365.

42. M. Colonna, C. Berti, M. Fiorini, E. Binassi, M. Mazzacurati, M. Vannini and S. Karanam, Green Chem., 2011, 13, 2543-2548.

43. M. A. Martin-Luengo, M. Yates, E. S. Rojo, D. Huerta Arribas, D. Aguilar and E. Ruiz Hitzky, Appl. Catal. A: Gen., 2010, 387, 141-146.

44. Q.-g. Zhang, L.-w. Bi, Z.-d. Zhao, Y.-p. Chen, D.-m. Li, Y. Gu, J. Wang, Y.-X. Chen, C.-y. Bo and X.-z. Liu, Chem. Eng. J., 2010, 159, 190-194.

45. A. R. Wilson, K. Sun, M. Chi, R. M. White, J. M. LeBeau, H. H. Lamb and B. J. Wiley, J. Phys. Chem. C, 2013, 117, 17557-17566.

46. M. Kamitsou, G. D. Panagiotou, K. S. Triantafyllidis, K. Bourikas, A. Lycourghiotis and C. Kordulis, Appl. Catal. A: Gen., 2014, 474, 224-229. 
Supplementary Information

Figure S1. Biomass feedstock OFMSW-1 as received at the plant.

Figure S2. Biomass OFMSW-2 as received at the plant

Figure S3. Inorganic material separated at different stages of the HTC process.

Figure S 4. OPW (left hand side) and PEP (right hand side) feedstocks.

Table S1. Ash composition (ash determination at $815^{\circ} \mathrm{C}$ ).

Table S2. Heavy metal content of the produced hydrochar samples.

Table S3. Conversions of the monoterpene mixture and product distribution for the dehydrogenation experiments with different catalysts at $320^{\circ} \mathrm{C}(1$ = paracymene). 